\title{
A HISTORICAL APPLICATION OF THE EXPORT-BASE MODEL: ECONOMIC IMPACTS OF AN INDIAN RESERVATION
}

\author{
Thomas $R$. Harris, Rangesan Narayanan, \\ Kambiz Raffiee, and Qingun Qi*
}

\begin{abstract}
This study addresses the problem of backcasting an export-base multiplier where data for earlier time periods do not exist. A procedure is outlined to backcast an export-base multiplier when the calculated export-base multiplier, using existing data, is found to be statistically unstable. An application is developed to estimate cumulative employment impacts in Churchill County, Nevada, as a result of nonperformance of a contract for delivered water between the Bureau of Reclamation and the Fallon Indians. Employment export-base multipliers were backcasted to 1910.
\end{abstract}

\section{INTRODUCTION}

Economic impacts to a local community from industrialization usually encompass changes in the level and distribution of employment, income, and other socioeconomic variables. In an attempt to quantify impacts of industrialization in rural areas, various impact models have been developed. Woods et al. (1983) present a detailed discussion and classification of such models. A common component of all of these economic impact models is that either export-base or inputoutput procedures are used to measure indirect impacts from industrialization.

Input-output and export-base models require historical data for estimation of economic linkages and sectoral multipliers. From historical data sets and forecasted direct impacts of industrialization, overall impacts to a rural economy from economic development activities can be derived. With development of microcomputer county-level employment and income data (U.S. Department of Commerce 1987) and microcomputer input-output model algorithms such as IMPLAN (Alward et al. 1989), ADOTMATR (Lamphear and Konecy 1986), or REMI (Treyz 1990), estimation of county-level export-base multipliers or inputoutput multipliers is less tedious than in the past. In addition, following the procedures of Burford and Katz (1977), input-output model multipliers may be estimated without a full input-output model.

\footnotetext{
*Associate Professor and Professor and Department Chair of Agricultural Economics, Associate Professor of Economics, and former Graduate Student of Agricultural Economics, University of Nevada, Reno, respectively. The research was conducted under funding from the Fallon Business Council of the Fallon Paiute/Shoshone Indian Reservation and the University of Nevada Agricultural Experiment Station Projects No. 219 and No. 205.
} 
All impact multiplier procedures discussed earlier are based in part on historic data. The impacts derived from such multiplier analyses are for future economic development or industrialization efforts. However, if export-base multiplier or input-output multipliers are desired for earlier time periods for which county-level data does not exist, impact models discussed earlier are not applicable. The question is then whether there are situations where researchers or community development practitioners desire to estimate export-base multipliers or input-output multipliers for past time periods. For example, this situation may occur if estimation of potential county-level impacts are desired for nonperformance of private or governmental contractual agreements. In this paper, an export-base multiplier was derived to estimate the county economic impacts from not meeting the contractual agreement to deliver irrigation water to the Fallon Indian (Paiute/Shoshone Tribe) Reservation in Churchill County, Nevada. These water deliveries were agreed upon by the tribe and the Bureau of Reclamation in 1902. The nonperformance of water deliveries not only impacts the tribal economy, but also the economy of Churchill County. Backcasting an export-base multiplier for Churchill County was a primary objective of this paper.

\section{STUDY AREA}

In 1887, under the General Allotment Act, the Indians who established residence in the Fallon area received 160 acres each for farming, for a total allotment of 31,000 acres. In 1906, many original allottees agreed to a contract with the U.S. Department of the Interior to exchange their 160-acre parcels for 10-acre tracts with paid out water rights and irrigation water deliveries to them. Irrigation water would be delivered to each of these tracts through the Newlands Irrigation Project, which was initiated by the U.S. Bureau of Reclamation in 1902 to provide water for the entire Lahontan Valley.

Water was first delivered to the Indian Reservation around 1910. Various problems, at first primarily associated with drainage, prevented full utilization of the water rights. A soil survey in 1932 indicated that 2,410 acres of reservation land were not irrigable. During the 1920s and 1930s, the Bureau of Reclamation constructed drainage systems for the purpose of improving drainage on the reservation. A soil survey in 1970 indicated that 1,600 acres were still not irrigable. Consequently, the Fallon Indian Reservation sought performance, including additional irrigable lands, since the original terms of the land exchange had not been met. In August 1978, the U.S. Congress enacted Public Law 95-337, which added 2,640 acres to the reservation as replacement for the nonirrigable lands in Fallon. Therefore, the question arises as to what the economic impacts would have been 
to Churchill County had water been delivered as contracted in 1910. Given this inquiry, procedures to estimate an export-base multiplier backwards through time are required. Therefore, the objective of this paper is to develop and estimate export-base multipliers for Churchill County where no data exist for earlier time periods.

\section{OVERVIEW OF EXPORT-BASE MODELS}

In export-base theory, it is argued that an economy is divided into two sectors-an export or basic sector and a nonexport or nonbasic sector. The export or basic sector is that portion of the local economy that trades with firms outside the local region. This export trade brings income to the area that, according to exportbase theory, generates future growth in the local economy. The nonexport or nonbasic industries sell their products within the local economy and exist to support export or basic industry activities. Therefore, expansion in export or basic economic sectors will likewise increase economic activity in the nonexport or nonbasic economic sectors.

Given time-series data and following procedures developed by Weiss and Gooding (1968), the export-base multiplier can be estimated by the following linear regression equation:

$$
E_{N B}=b E_{B}+e
$$

where $E_{N B}$ is the nonbasic sector employment, $E_{B}$ is the basic sector employment, the coefficient $b$ indicates the change in nonbasic employment from $a$ change in basic employment, and $e$ is the error term. The export-base multiplier is derived by adding one to the regression coefficient, or $(1+b)$, which represents the response in total county or regional employment from a one-unit change in basic sector employment.

Past literature on export-base multipliers has investigated the measurement of the economic base and the stability of the export-base multiplier (Richardson 1985). A major issue with economic-base models is the measurement of the economic base in order to calculate the nonbasic sector. Estimation of the economic base has drawn upon both primary surveys (Richardson 1985) and secondary data procedures such as location quotients (Isserman 1980), minimum requirements (Ullman and Darcey 1960), assignment models (Isserman 1980), time-series data and ordinary least squares regression (Mathur and Rosen 1974), and estimation of export shares (Stevens et al. 1979). While questions pertaining 
to the accuracy of the economic base estimated through secondary procedures exist (Richardson 1985), the primary survey procedure has proved to be time consuming and expensive.

Numerous studies have investigated the temporal nature of the export-base multiplier. Shahidsaless et al. (1983), Shaffer (1983), Braschler (1972), McNulty (1977), and Mandelbaum and Chicoine (1985) have used cross-sectional analysis to investigate the existence of short-term and long-term export-base multipliers. In studies by Shahidsaless et al. (1983), Shaffer (1983), and Braschler (1972), it was found that a 10-year multiplier was acceptable. McNulty (1977) tested the appropriate time frame for estimating export-base multipliers using annual personal income estimates for standard metropolitan statistical areas (SMSAs). McNulty (1977) found export-base theory appropriate for long-term regional growth but not applicable to short-term economic development. Mandelbaum and Chicoine (1985) found that for smaller nonmetropolitan counties in Illinois, export-base multipliers explained the data reasonably well in both the long run and the short run. However, for larger nonmetropolitan Illinois counties, inconsistent model estimates were obtained for periods longer than four years.

Henry and Nyankori (1981), Cook (1979), Spreen and Mulkey (1980), and Giarrantani and McNelis (1980) used time-series analysis to investigate the existence of short-term and long-term export-base multipliers. Cook (1979) applied a transfer function to quarterly employment data in two Washington counties. Cook found that nonbasic employment lagged growth in basic sector employment. Using quarterly state data, Spreen and Mulkey (1980) found no statistically significant lags between basic and nonbasic employment series. Giarrantani and McNelis (1980) performed the Granger test of causality and found little evidence of basic sector income changes causing nonbasic income changes in South Atlantic states. Using monthly data and spline procedures, Henry and Nyankori (1981) found the existence of a short-term multiplier for the Greenville-Spartanburg SMSA. Also, they found evidence that basic employment changes will affect nonbasic employment changes over a two-year period. However, none of these studies addressed the problem of estimating an export-base multiplier backward through time when historical data are not available.

\section{PROCEDURES}

The estimated multiplier or regression coefficient is regarded as an estimated average base multiplier for the time period of the data series. The multiplier effect may change over time due to change in the overall economic structure. Therefore, an estimated multiplier from one period may not be appropriate for another period 
unless there is evidence that significant changes have not occurred over time. If the base multiplier proves to be stable in this sense, then the estimated multiplier can be used for the entire time horizon. For the Churchill County example, a stable multiplier could be used for past periods where no data exist. However, if there is evidence that the estimated multiplier changes over time, then it cannot be used for other subperiods in which data did not exist.

Stability of the Churchill County export-base multiplier will be tested using a recursive residuals procedure. The recursive residual technique is an appropriate method of discovering structural changes when time-series data are involved and when the speed of the structural change is unknown. The recursive residual procedure estimates a series of regressions by adding one observation per regression. If the regression coefficient or export-base multiplier is stable over time, the recursive residuals of these regressions will be normally and independently distributed with a zero mean and a constant variance (Harvey 1981; Brown et al. 1975). The recursive residual test is simple in that it does not require a prior specification of the occurrence of structural change. When compared to the Chow-test, the power of the recursive residual test is quite limited. However, the Chow-test is based on definite information regarding the occurrence of structural change. If the speed of structural change is not known or must be estimated, then the advantage of the Chow-test is diminished considerably (Greene 1990). Because of uncertainty regarding the occurrence of structural change in Churchill County, the stability of the coefficient of the export-base multiplier is tested using the calculated Harvey's t-value from recursive residuals. If the calculated Harvey's t-value exceeds the critical value, it is concluded that the regression coefficient or exportbase multiplier is unstable, and an alternative procedure must be used. The suggested procedure is described below.

If the Churchill County export-base multiplier is found to be unstable, the following procedures will be employed. First, the available data set will be divided into two equal subgroups, and a multiplier will be estimated for each. Second, it is assumed that the export-base multiplier is time-varying and has a constant annual rate of change. Third, Equation (2) will be used to estimate the export-base multiplier through time:

$$
\mathrm{M}_{\mathrm{t}}=\mathrm{ke}^{\mathrm{tr}}
$$

where $\mathrm{k}$ is a constant term, $\mathrm{t}$ is the time variable year, $\mathrm{r}$ is the annual rate of change for the export-base multiplier, and $\mathrm{M}_{\mathrm{t}}$ is the multiplier for time period $t$.

After estimating export-base multiplier coefficients for the two subgroups and defining the middle year for each, two equations and two unknowns will be defined as shown in Equations (3) and (4): 


$$
\begin{aligned}
& M_{1}=k e^{t} 1^{r} \\
& M_{2}=k e^{t} 2^{r}
\end{aligned}
$$

where $t_{1}$ is the middle year for the first subgroup, $t_{2}$ is the middle year for the second subgroup, $\mathbf{M}_{1}$ is the export-base multiplier for the first subgroup, and $\mathbf{M}_{2}$ is the export-base multiplier for the second subgroup.

By solving the simultaneous Equations (3) and (4), $\mathrm{r}$ and $\mathrm{k}$ are derived. Once $r$ and $k$ are derived, an export-base multiplier for any year can be calculated using Equation (2).

\section{RESULTS OF MULTIPLIER ANALYSIS}

Although the reservation economy is small relative to Churchill County's economy in terms of income and employment levels, Churchill County benefits from the demands and production levels generated by members of the tribe residing in the area. Therefore, activities generated within the reservation would be captured in the Churchill County economic data.

An export-base multiplier was derived for Churchill County using annual sectoral employment data from 1969 to 1986 generated by the U.S. Department of Commerce (1987). The allocation, location quotient, and minimum requirements procedures were employed to derive basic sector employment and export-base multiplier for Churchill County. Using the allocation method, the agricultural, mining, manufacturing, and federal government sectors were designated as basic sectors. All other sectors were designated as nonbasic sectors. Procedures outlined by Isserman (1980) were used to assign basic sector employment by the location quotient and minimum requirements procedures. ${ }^{1}$

Table 1 shows the estimated export-base multiplier for Churchill County from 1969 to 1986 using these three procedures. For any of the three estimated export-base multipliers to be used for all time periods, the stability of each regression equation must be tested. Recursive residuals were estimated for the three regression equations from 1969 to 1986, and the calculated Harvey's forward and backward recursive-t are shown in Table 1. With 16 degrees of freedom, the null hypothesis of stability for each of the three export-base multiplier equations was rejected.

Therefore, the export-base multiplier estimated by each of the three regression equations was found to be statistically unstable and thus could not be used for the entire study period. The export-base multiplier derived from the minimum requirements procedure was selected for the analyses below. ${ }^{2}$ Using the export- 
TABLE 1

Estimated Export-Base Multiplier for Churchill County, Nevada, Using the Allocation, Location Quotient, and Minimum Requirements Procedures

Allocation Procedure:

$\mathrm{E}_{\mathrm{NB}}=\underset{(29.38)}{1.6870 \mathrm{E}_{\mathrm{B}}} \quad \mathrm{R}^{2}=0.6257$

Harvey's Forward Recursive-t $\quad=\quad 4.7584$

Harvey's Backward Recursive-t $\quad=\quad-5.7835$

Location Quotient Procedure:
$\mathrm{E}_{\mathrm{NB}}=1.511 \mathrm{~EB}_{\mathrm{B}}$
(24.47)
Harvey's Forward Recursive-t $\quad=\quad 6.4206$
Harvey's Backward Recursive-t $\quad=\quad-5.8696$

$R^{2}=0.5303$

Minimum Requirements Procedure:
$\mathrm{E}_{\mathrm{NB}}=0.99099 \mathrm{E}_{\mathrm{B}}$
$\mathrm{R}^{2}=0.9682$
(118.65)
Harvey's Forward Recursive-t
$=3.8247$
Harvey's Backward Recursive-t
$=-3.2477$

base multiplier derived through the minimum requirements procedure and given the instability of this multiplier, procedures outlined above to estimate the exportbase multiplier through time will be employed.

The Churchill County employment data were divided into two subgroups: 1969-1977 and 1978-1986. The export-base multiplier for each subgroup is presented below:

Subgroup 1 (1969-1977):

$$
\mathrm{E}_{\mathrm{NB}}=0.97033 \mathrm{E}_{\mathrm{B}} \quad \mathrm{R}^{2}=0.9070
$$


Subgroup 2 (1978-1986):

$$
\mathrm{E}_{\mathrm{NB}}=\begin{aligned}
& 1.0023 \mathrm{E}_{\mathrm{B}} \\
& (87.541)
\end{aligned} \quad \mathrm{R}^{2}=0.9215
$$

The average multiplier for the first subgroup (1969-1977) is 0.97033, and 1973 will represent the midyear for this subgroup, or $t_{1}=73$. For the second subgroup (1978-1986), the average multiplier is 1.0023 and $t_{2}=83$. Using this information, a system of simultaneous equations similar to Equations (3) and (4) can be derived or:

$$
\begin{aligned}
& \mathrm{ke}^{73 \mathrm{r}}=0.97033 \\
& \mathrm{ke}^{83 \mathrm{r}}=1.0023
\end{aligned}
$$

Solving these equations results in $k=0.765646$ and $r=0.003245$. Given these values and Equation (2), the formula to derive the export-base multiplier through time for Churchill County is:

$$
M_{t}=0.765646 \mathrm{e}^{0.003245 \mathrm{t}}
$$

Based upon Equation (9), the estimated export-base multiplier for Churchill County ranges from 0.79089 (total multiplier of 1.79089 ) in 1910 to 1.018689 (total multiplier of 2.018689) in 1988.

\section{ESTIMATION OF EMPLOYMENT IMPACTS TO CHURCHILL COUNTY}

From historical records, yield and labor productivity were estimated to derive historical levels of agricultural production and employment. Using these relationships and the estimated multiplier above, employment impacts within Churchill County from nondeliveries of surface water to the Indian reservation were derived.

Within the reservation, alfalfa is the primary agricultural product. Relatively little acreage exists in irrigated pasture, vegetables, and small grains. For the purpose of this study, it is assumed that alfalfa hay is grown on all lands with an average stand life of eight years, followed by a two-year rotation of oat hay. 
During certain time periods of the reservation's history, dairy and beef cattle operations existed; however, accurate livestock production data were not available for these time periods. With this in mind, the assumptions made on the cropping pattern and rotation appear to be consistent with the historic agricultural practices on the reservation.

Time-series information on alfalfa hay yields for the reservation was not available and thus had to be estimated. Yield growth rates over time were also estimated for the state and Churchill County. County yields have been growing at 1 percent per annum from 1936 to 1960 and have since slowed to approximately 0.7 percent annual growth. The growth rate in state yields for the same time periods has been 1.4 percent and 0.8 percent, respectively. These figures suggest that future growth in yields on the reservation would be relatively small. Finally, historical labor productivity was derived as the index of farm production per hour by selected commodity groups for the United States from 1910 to 1988 from the United States Department of Agriculture (1991).

Average yields for Churchill County are dependent upon the acreage of the various land classes that are being irrigated. The countywide average yield estimates cannot be directly used for yields on the reservation since the proportion of different land classes on the reservation are likely to be different from the countywide proportions. Using the Soil Survey for Churchill County (United States Department of Agriculture 1975), land class proportions were estimated in comparable terms to the land classes defined for the reservation lands. It was estimated that 25 percent constituted class I land, another 25 percent class II land, and 50 percent could be designated as class III land. Also assuming that class I yields were 100 percent, class II yields were 91 percent of class I land, and class III yields were 82 percent of class I land (United States Department of Interior 1986), yields for various land classes on the reservation are estimated.

Using these data, estimation of lost employment in Churchill County from the less than full allocation of irrigation water was derived. For 1910, if all water had been delivered, 4,460 acres would have been planted in alfalfa hay. From the land survey, it was estimated that of the 4,460 acres, 276 acres were class I land yielding 3.09 tons per acre, 1,194 acres were class II land yielding 2.81 tons per acre, and 3,170 acres were class III land yielding 2.53 tons per acre. However, only 983 acres were irrigated in 1910, of which 276 acres were class I land yielding 3.09 tons per acre, 707 acres of class II land yielding 2.81 tons per acre, and no acres were planted in class III land. Based upon these relationships, total output to the reservation was estimated to be 12,228 tons under the full allocation and 2,733 tons under the realized allocation.

Using the alfalfa hay extension costs and returns budget for 1990, the estimated labor per ton of alfalfa in 1990 was 0.01938 . Labor productivity, of 
course, was lower in 1990 and was estimated to be 0.11603 . Based upon these values, the total estimated labor hired under the full allocation would have been 1,419 employees versus 317 employees under the actual allocation. Using the direct employment estimates for the two scenarios and the estimated export-base multiplier for 1910 (1.79089), total employment impacts under full allocation in 1910 would have been 2,541 employees versus 568 employees under the actual allocation, for a difference of 1,973 employees.

Similar procedures were used throughout the analysis to derive cumulative loss in employment for Churchill County from 1910 to 1988. Actual irrigated acreage data were available only for selected years. Therefore, linear interpolation was used to estimate irrigated acreage for years without data. Irrigated acreage increased from 945 acres in 1908 to 2,762 acres in 1988. Using procedures described earlier, cumulative direct employment if full allocation was realized from 1910 to 1988 would have been 80,805 person-years. Given that actual cumulative employment was 28,970 person-years, a direct employment loss of 51,835 person-years can be attributed to the shortfall in water allocation. Finally, based upon the employment multipliers derived for each year from Equation (9), the total cumulative employment impact to Churchill County from the nondelivery of surface water was 101,427 person-years, of which 49,592 was an indirect impact.

\section{CONCLUSIONS}

The estimation of impacts from rural industrialization has been of interest to rural economic development researchers and practitioners for many years. Usually, impacts are estimated for future economic development projects such as the relocation of new industry or governmental projects. The impact models used for these analyses are developed from historical employment and income data to derive responses and linkages of rural economic sectors.

However, if impacts are desired for past time periods from projects that were either partially or not completed, these impact models are of little use. Therefore, this study addresses the problem of backcasting of an export-base multiplier where data from earlier time periods do not exist. If the export-base model estimated with existing data proves to be statistically unstable, the export-base multiplier derived from existing data should not be used during the historical period. Procedures outlined in this study provide a methodology to backcast an exportbase multiplier when such a multiplier is unstable.

Using the procedures outlined in this study, the export-base employment multiplier was derived for Churchill County, Nevada. The growth rate of the mul- 
tiplier was 0.3245 percent per year, and the total multiplier varied from 1.79 in 1910 to 2.02 in 1988. Estimates of potential job losses in Churchill County as a result of nonperformance of the contract for water delivery between the Bureau of Reclamation and the Fallon Indians was derived based on this analysis. Direct cumulative loses were estimated to be 51,835 person-years for the time period spanning 1910-1988. Corresponding indirect cumulative losses for the county amounted to an additional 49,592 person-years over this period.

\section{ENDNOTES}

1. Using location quotient procedures, employment was allocated between basic and nonbasic sector employment using national employment as the reference group. Allocation of basic and nonbasic sector employment using minimum requirements employed procedures outlined by Braschler and Kuehn (1976) for counties with no communities with populations of 2,500 or more.

2. The minimum requirements procedure was chosen for numerous reasons. First, the results from the minimum requirements procedure proved to have a superior measure of goodness-of-fit $\left(\mathrm{R}^{2}=0.9682\right)$, with a higher calculated student-t statistic for the export-base multiplier as compared to regression results in Table 1 for the allocation and location quotient procedures. Second, comparison of regression results for the export-base multiplier for each subgroup was superior for the minimum requirements procedure. For the allocation procedure, the export-base multiplier is presented below:

Subgroup 1 (1969-1977) Allocation Procedure:

$\mathrm{E}_{\mathrm{NB}}=\begin{aligned} & 1.4478 \mathrm{E}_{\mathrm{B}} \\ & (30.094)\end{aligned} \quad \mathrm{R}^{2}=0.017$

Subgroup 2 (1978-1986) Allocation Procedure:

$\mathrm{E}_{\mathrm{NB}}=\begin{aligned} & 1.8594 \mathrm{E}_{\mathrm{B}} \\ & (47.696)\end{aligned} \quad \mathrm{R}^{2}=0.767$

3. Annual U.S. all-hay yields and Nevada alfalfa hay and alfalfa hay mixture yield data were available from 1939 to 1988 (United States Department of Agriculture, various issues). Using this data, the relationship between Nevada hay and alfalfa hay mixtures and the U.S. all-hay yield was derived from the fol- 
lowing regression equation:

$$
\mathrm{NAY}=\underset{(7.8)}{1.2952}+\underset{(10.9)}{0.99454 \text { USHAY }} \quad \mathrm{R}^{2}=0.7329
$$

where NAY is Nevada alfalfa hay and alfalfa hay mixture yield, and USHAY is the U.S. all-hay yield.

The regression results indicate that Nevada yields are approximately 1.3 tons per acre higher than U.S. all-hay yields.

From Nevada Agricultural Statistics (Nevada Agricultural Statistics Service, various issues), 17 years (from 1969 to 1988) of alfalfa hay yield data for the state and Churchill County were acquired. Based upon this data, a regression model was estimated explaining the relationship between Churchill County alfalfa yields and Nevada alfalfa yields:

$$
\text { CAY }=\underset{(1.35)}{0.74517}+\underset{(6.16)}{0.96394 N A Y} \quad R^{2}=0.7164
$$

where CAY is Churchill County alfalfa hay and alfalfa hay mixture yield.

Results from the regression model indicate that Churchill County yields are on average 0.75 tons per acre higher than the state average. Based on these estimation results, Churchill County alfalfa yields are extrapolated from 1988 to 1908. Oat hay yields were assumed to be a fraction of the estimated alfalfa yields for the county, and a weighted average yield for alfalfa/oat hay rotation was estimated.

4. Labor productivity was derived for the hay and forage enterprise group to represent Nevada alfalfa hay. An alfalfa hay agricultural extension budget for Churchill County (Wheeler and Myer 1990) was used to derive the amount of labor required per ton of alfalfa hay production. Using labor requirements from the extension budget along with the labor productivity index, historical labor requirements per ton of alfalfa hay production were estimated.

\section{REFERENCES}

Alward, G. E. Siverts, D. Olson, J. Wagner, D. Snef, and S. Lindall. Micro IMPLAN: Software Manual. Fort Collins, Colo.: U. S. Forest Service, Colorado State University, 1989. 
Braschler, C. "A Comparison of Least Squares Estimates of Regional Employment Multipliers with Other Methods." Journal of Regional Science 13 (1972): 61-73.

Braschler, C., and J. Kuehn. "Estimation of Employment Multipliers for Planning in Ozarks Nonmetropolitan Counties." Southern Journal of Agricultural Economics 8 (1976): 187-192.

Brown, R., J. Durbin, and J. Evans. "Techniques for Constancy of Regression Relationships Over Time." Journal of the Royal Statistical Society 37 (1975): 149-192.

Burford, R., and J. Katz. "Regional Input-Output Multipliers Without a Full I-O Table." Annals of Regional Science 11 (1977): 21-38.

Cook, T. "An Application of the Transfer Function to an Economic-Base Model." Annals of Regional Science 13 (1979): 81-92.

Giarrantani, F., and P. McNelis. "Time Series Evidence Bearing on Crude Theories of Regional Growth." Land Economics 56 (1980): 238-248.

Greene, W. Econometric Analysis. New York: Macmillan Publishing Company, 1990.

Harvey, A. The Econometric Analysis of Time Series. New York: Halstead Press, 1981.

Henry, M., and J. Nyankori. "The Existence of Short-Run Economic Base Multipliers: Some New Empirical Evidence." Land Economics 57 (1981): 448-458.

Isserman, A. "Estimating Export Activity in Regional Economy: A Theoretical and Empirical Analysis of Alternative Methods." International Regional Science Review 5 (1980): 155-184.

Lamphear, F., and R. Konecy. ADOTMATR's User's Manual. Lincoln, Nebr.: University of Nebraska, 1986.

Mandelbaum, T., and D. Chicoine. "The Effect of Time Frames in the Estimation of Employment Multipliers." Selected Paper at the American Agricultural Economics Association Meeting, Ames, Iowa, 1985.

Mathur, V., and H. Rosen. "Regional Employment Multipliers: A New Approach." Land Economics 50 (1974): 93-96.

McNulty, J. "A Test of the Time Dimension in Economic Base Analysis." Land Economics 63 (1977): 358-368.

Nevada Agricultural Statistics Service. Nevada Agricultural Statistics Yearbook. Reno, Nev.: Nevada Department of Agriculture, various issues.

Richardson, H. "Input-Output and Economic Base Multipliers: Looking Back and Forward." Journal of Regional Science 25 (1985): 607-661. 
Shahidsaless, S., W. Gillis, and R. Shaffer. "Community Characteristics and Employment Multipliers in Nonmetropolitan Counties, 1950-1970." Land Economics 59 (1983): 84-93.

Shaffer, R. "A Test of the Difference in Export Base Multipliers in Expanding and Contracting Economies." Regional Science Perspectives 13 (1983): 61-73.

Spreen, T., and D. Mulkey. "The Lagged Effect of Basic Sector Employment Change in a Regional Economy." Paper presented at the Southern Regional Science Association Meetings, Savannah, Georgia, 1980.

Stevens, B., G. Treyz, and D. Ehrlich. "On the Estimation of Regional Purchase Coefficients, Export Employment and Elasticities of Response for Regional Economic Models." Regional Science Research Institute Discussion Paper 114, Amherst, Mass.: Regional Science Research Institute, 1979.

Treyz, G. Multiregion EDFS-53 and FS-53: Operator's Manual, Volume 2. Amherst, Mass.: Regional Economic Models Incorporated, 1990.

Ullman, E., and M. Darcey. "The Minimum Requirements Approach to the Urban Economic Base." Paper, Regional Science Association 6 (1960): 174-194.

United States Department of Agriculture. Soil Survey in Fallon-Fernley Area, Nevada. Washington, D.C.: Soil Conservation Service, 1975. . Economic Indicators of the Farm Sector: Production and Efficiency Statistics, 1989. Washington, D.C.: National Economics Division, Economic Research Service, 1991.

Agricultural Statistics Yearbook. Washington, D.C.: United States Government Printing Office, various issues.

United States Department of Commerce. Regional Economic Information System.

Washington, D.C.: Bureau of Economic Analysis, 1987.

United States Department of Interior. Fallon Indian Reservation Land

Classification Delivery Order. Bureau of Reclamation, Mid-Pacific Region, Sacramento, California, CH2M Hill, 1986.

Weiss, S., and E. Gooding. "Estimation of Differential Employment Multipliers in a Regional Economy." Land Economics 44 (1968): 235-244.

Wheeler, G., and G. Myer. Alfalfa Production Costs for Fallon, Nevada Area. University of Nevada Cooperative Extension, University of Nevada, Reno. Fact Sheet 90-36, 1990.

Woods, M., G. Doeksen, and L. Jones. "A Presentation and Comparison of Three Computer Models Developed to Model the Social and Economic Impacts of Rural Community Growth." The Review of Regional Studies 13 (1983): 22-31. 